\title{
2D Interwoven Metal-Organic Framework in Tetrachloromercurate(II) based Hybrid Material
}

\author{
MUKESH KUMAR ${ }^{1}$, SANJAY K. VERMA ${ }^{1}$, BIKRAM SINGH ${ }^{2}$, \\ ATUL THAKUR $^{2}$, AJIT KUMAR ${ }^{1}$ and DINESH JASROTIA ${ }^{1 *}$ \\ ${ }^{1}$ Department of Physics, Govt. G. M. Science College, Jammu (J \& K)-180016, India \\ ${ }^{2}$ School of Physics \& Materials Science, Shoolini University, Solan (H.P)-173212, India \\ phy.dinesh.ap@gmail.com
}

Received 15 December 2014 / Accepted 29 December 2014

\begin{abstract}
The secondary interactions bonded crystal structure of $p$-phenylenediammonium tetrachloromercurate(II) has been studied by X-ray diffraction techniques and hyper-Raman Tensor studies. The tetrahedra hybrid structure exhibit two dimensional interwoven inorganic-organic layers mingle through $\mathrm{N}-\mathrm{H}$... Cl hydrogen bonding interactions. Organic layers are squash-in between $\mathrm{Cl}$...Cl halogen bonded inorganic layers in $p$-phenylenediammonium tetrachloromercurate(II) with $\mathrm{Cl} \ldots \mathrm{Cl}$ distance $=3.628(3) \AA$ and $\mathrm{Hg}-\mathrm{Cl} \ldots \mathrm{Cl}=157.8(9)^{\circ} . \mathrm{H} 2 \mathrm{~A}$ atom is shared by two chlorine atoms [Cl1 and $\mathrm{Cl} 3$ ] and thus acts as bifurcated hydrogen atom with bifurcated hydrogen bond angle of $93.98(6)^{\circ}$. The antiparallel zig-zag bilayer inorganic-organic pattern present the $p$ phenylenediammonium tetrachloromercurate(II) into two-dimensional pattern along the ac-plane. The nearest centroid-centroid distance [3.86(4) $\AA$ ] depicts that the contact is outlying to have any $\pi . . . \pi$ interactions and the nearest hydrogen to centroid distance $[2.82(3) \AA]$ contributes to stability of crystal structure through $\mathrm{C}-\mathrm{H} . . . \pi$ interactions. The initial Hyper-Raman tensors were calculated through polarization selection rules by using crystallographic Wyckoff positions.
\end{abstract}

Keywords: Hybrid materials, N-H...Cl hydrogen bonding, 2D Interwoven pattern.

\section{Introduction}

The study of hybrid organic-inorganic materials is a recent but very fruitful and prolific enterprise ${ }^{1}$. The organic-inorganic hybrids are the materials that combine desirable physical properties of both organic and inorganic components within the single composite ${ }^{2}$. These hybrids are of interest due to their self-assembled organic-inorganic layered structures which causes variation in their structural, magnetic, optical and electrical properties, particularly since these can be modified by replacement of the metal, halide or amine $\mathrm{e}^{3-4}$. The desire to design rationally technologically useful solid-state materials has led to a recent surge of interest in the concept of crystal engineering ${ }^{5-7}$, a cross disciplinary area that necessarily involves chemists (synthetic, physical, computational, theoretical and analytical), crystallographers and physicists and is of particular relevance to materials scientists. $A b$ - initio prediction of crystal structures on purely theoretical grounds is not yet feasible ${ }^{8}$; 
however, our ever growing understanding of the nature of intermolecular interactions and molecular recognition processes is providing the background knowledge that makes crystal engineering both a realistic and ultimately an achievable goal.

In recent years, the design and synthesis of metal-organic frameworks (MOF) based on the assembly of suitable and rigid building blocks have attracted great attention ${ }^{9-14}$. The design of polymeric coinage $\mathrm{d}^{10}$ metal complexes with fascinating structures has also received much attention ${ }^{15-19}$, indicating in some studies that direct metal-metal interactions are among the most important factors for the manifestation of such structures. Between closed-shell species, no strong attractions are expected and, in fact, two closed-shell metal cations will normally repel each other. However, in the case of some coordination compounds, metal-metal attractions, also called 'metallophilic' interactions, are present. These interactions have strengths similar to typical hydrogen bonds ${ }^{20}$.

A very large number and variety of intermolecular interactions have been used in crystal engineering. Most notable among such interactions are hydrogen bonds. The hydrogen bond is especially important because it is strong and directional ${ }^{21}$. Therefore it is a very effective design element in crystal engineering. A very large variety of hydrogen bonds are known. In addition to the stronger variety such as $\mathrm{O}-\mathrm{H} \cdots \mathrm{O}$ and $\mathrm{N}-\mathrm{H} \cdots \mathrm{O}$ there are weaker varieties like $\mathrm{C}-\mathrm{H} \cdots \mathrm{O}, \mathrm{N}-$ $\mathrm{H} . . . \mathrm{Cl}, \mathrm{C}-\mathrm{H} \cdots \pi$ and other varieties that incorporate metal atoms, multiple atom acceptors and other donor and acceptor groups of very feeble effectiveness ${ }^{22}$. These hydrogen bonds have a greater or lesser effect on the outcome of the final crystal structure. Other interactions that have become popular in recent times include halogen bonds in which an electrophilic halogen atom plays the same role as the hydrogen atom does in a hydrogen bond ${ }^{23}$. Interactions between halogen atoms such as $\mathrm{Cl} \cdots \mathrm{Cl}, \mathrm{Br} \cdots \mathrm{Br}$ and $\mathrm{I} \cdots \mathrm{I}$ are special cases of halogen bonding ${ }^{24-26}$. It has become obviously clear that halogen...halogen interaction could very well be utilized as a design element of hybrid materials in crystal engineering. As a part of our ongoing research on crystal engineering of hybrid materials ${ }^{27-30}$, the title material has been analyzed.

\section{Experimental}

Single Crystal Growth

The synthesis of this hybrid material has been carried out by using the following reaction scheme:

$$
\begin{gathered}
\mathrm{HgCl}_{2}+2 \mathrm{RNH}_{2}+2 \mathrm{HCl} \rightarrow\left(\mathrm{RNH}_{3}\right)_{2} \mathrm{HgCl}_{4} \\
\mathrm{R} \rightarrow p \text {-Phenylenediammonium }
\end{gathered}
$$

Generally, the ratio of metal halide to monoamine to acid halide is 1 to 2 to 2 . The two most successful techniques for growing crystals are solution growth (SG) and slow cooling $(\mathrm{SC})^{31}$. All compounds have been obtained commercially and used without further purification.

The compound of $p$-Phenylenediammonium tetrachloro mercurate(II) has been prepared by adding $0.092 \mathrm{~g}$ of $\mathrm{HgCl}_{2}$ and $0.102 \mathrm{~g}$ of $p$-phenylenediammonium in $5 \mathrm{~mL}$ of $\mathrm{HCl}$. The complete dissolution has been obtained after refluxing at $95^{\circ} \mathrm{C}$ for 12 hours. Slow cooling over 48 hours produced the crystals. A colourless crystal of size $0.35 \times 0.20 \times 0.15 \mathrm{~mm}$ has been mounted on a glass fibre for X-ray diffraction data.

The compound of $p$-phenylenediammonium tetrachloromercurate(II) has been prepared by adding mercuric chloride $[0.092 \mathrm{~g}]$ and $p$-phenylenediammonium $[0.102 \mathrm{~g}(0.333 \mathrm{mmol})]$ into a glass sample vial and $5 \mathrm{~mL}$ of hydrochloric acid $[33 \% \mathrm{HCl}]$ has been added in the vial. Precipitates have been formed and solution hasn't been dissolved at room temperature even being submersed in an ultrasound bath. 
The vial has been heated in oil bath that is controlled by a programmable temperature controller. The oil bath has been heated up to $95^{\circ} \mathrm{C}$ and then held constant at that temperature for 12 hours, until all the precipitates dissolved.

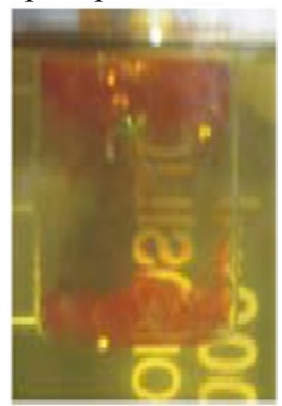

Figure 1. Picture depicts orange coloured plate-like crystals of the hybrid material.

The sample has then been sealed with its polytop lid and the height of the vial in the oil bath adjusted such that the vial is only immersed up to the level of the solution inside the vial. Slow cooling in the oil bath over 48 hours produced the crystals at the upper half of the vial (Figure 1). The thin plate shaped crystals have been extracted and dried.

\section{Structure analysis}

Single crystal X-ray crystallographic techniques have been employed for the crystal structure determination and refinement. Morphologically perfect single crystal has been selected for the three-dimensional X-ray diffraction data by using X-calibur CCD Diffractometer. The structure determination has been carried by SHELXS program ${ }^{32}$ whereas the least-squares refinement has been contemplated by using SHELXL program ${ }^{33}$ for the precise values of R-factor [0.0551].

All the non-hydrogen atoms of the molecule have been located from E-map. The positional and thermal parameters of non-hydrogen atoms have been refined anisotropically. All the hydrogen atoms included in the final cycles of the refinement have been constrained to ride on their parent atoms, with $\mathrm{U}_{\text {iso }}(\mathrm{H})=\mathrm{X} \mathrm{U}_{\mathrm{eq}}$ (parent), where $\mathrm{X}=1.5$ for methyl and 1.2 for all others. Constrained distances were $\mathrm{O}-\mathrm{H}=0.82 \AA, \mathrm{N}-\mathrm{H}=0.91 \AA$ and $\mathrm{C}-\mathrm{H}=0.95 \AA$. The crystal data for the compound has been presented in Table 1. Atomic coordinates and equivalent isotropic displacement parameters for $p$-phenylenediammonium tetrachloro-mercurate(II) has been shown in Table 2 and powder diffraction pattern depicting the peak intensity is shown in Figure 2. The $3 \mathrm{D}$ view depicting the atomic numbering scheme of compound is presented in Figure 3.

Table 1. Crystal data for $p$-phenylenediammonium tetrachloromercurate(II).

\begin{tabular}{ll}
\hline Chemical Name & $p$-Phenylenediammonium tetrachloromercurate(II) \\
\hline Emperical formula & $\mathrm{C}_{6} \mathrm{H}_{10} \mathrm{~N}_{2} \mathrm{HgCl}_{4}$ \\
Formula weight & 452.55 \\
Crystal system & Monoclinic \\
Space group & $\mathrm{C} 2 / \mathrm{c}$ \\
Unit cell dimensions & $\mathrm{a}=18.468(2), \mathrm{b}=6.292(1), \mathrm{c}=20.744(2) \AA$, \\
& $\alpha=90.00^{\circ}, \beta=106.1(1)^{\circ}, \gamma=90.00^{\circ}$ \\
Volume, $\mathrm{Z}$ & $2316.2(4), 8$ \\
Melting point & $461 \mathrm{~K}$ \\
Temperature $(\mathrm{K})$ & $173(2)$ \\
Wavelength $(\lambda)$ & 0.71073 \\
\hline
\end{tabular}


Table 2. Atomic coordinates and equivalent isotropic displacement parameters $\left(\AA^{2}\right)$ for pPhenylenediammonium tetrachloromercurate(II).

\begin{tabular}{ccccc}
\hline Atom & $\mathrm{x}$ & $\mathrm{y}$ & $\mathrm{z}$ & $\mathrm{U}_{\text {iso }}$ \\
\hline $\mathrm{Hg} 1$ & $0.407(2)$ & $-0.026(1)$ & $0.047(2)$ & $0.029(2)$ \\
$\mathrm{Cl} 3$ & $0.376(1)$ & $-0.060(3)$ & $-0.073(1)$ & $0.026(4)$ \\
C12 & $0.440(1)$ & $0.386(3)$ & $0.047(1)$ & $0.024(4)$ \\
C11 & $0.263(1)$ & $0.009(3)$ & $0.061(1)$ & $0.024(4)$ \\
C14 & $0.472(1)$ & $-0.136(3)$ & $0.159(1)$ & $0.023(4)$ \\
C1 & $0.329(4)$ & $0.510(1)$ & $0.179(4)$ & $0.021(1)$ \\
C2 & $0.374(4)$ & $0.350(1)$ & $0.216(4)$ & $0.027(2)$ \\
C3 & $0.396(4)$ & $0.365(1)$ & $0.285(4)$ & $0.028(2)$ \\
C4 & $0.371(4)$ & $0.534(1)$ & $0.316(4)$ & $0.021(1)$ \\
C5 & $0.325(4)$ & $0.690(1)$ & $0.279(4)$ & $0.026(2)$ \\
C6 & $0.304(4)$ & $0.676(1)$ & $0.209(4)$ & $0.028(2)$ \\
N1 & $0.308(4)$ & $0.497(1)$ & $0.105(4)$ & $0.024(1)$ \\
N2 & $0.395(4)$ & $0.556(1)$ & $0.389(3)$ & $0.024(1)$ \\
\hline
\end{tabular}

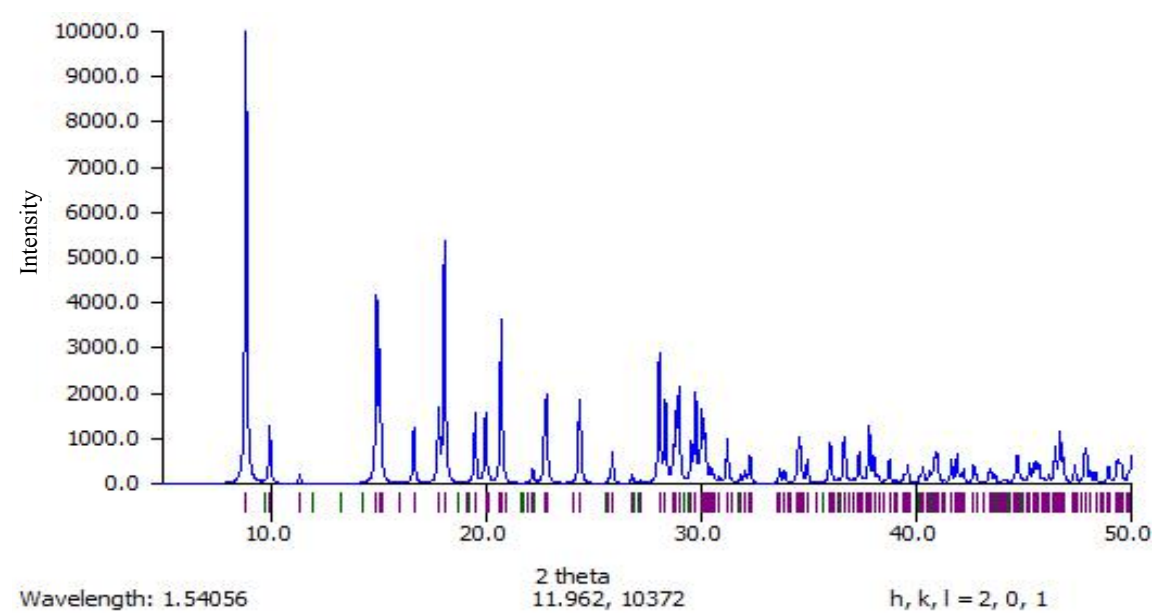

Figure 2. Powder Diffraction Pattern for $p$-phenylenediammonium tetrachloromercurate(II) depicting the peak intensity.

\section{Results and Discussion}

The molecular geometry and atomic numbering schemes employed for $p$ phenylenediammonium tetrachloromercurate(II) are illustrated in Figure 3. In solid state, $p$-phenylenediammonium tetrachloromercurate(II), self-assemble into structures consisting of alternating organic layers, made up of $p$-phenylenediammonium and inorganic layers made up of tetrachloromercurate.

The X-ray diffraction structure analysis of a single crystal of compound $p$ phenylenediammonium tetrachloromercurate(II) revealed that the inorganic part of the structure contains four chlorine atoms annexed with mercury to form a tetrahedron, in which all the $\mathrm{Hg}-\mathrm{Cl}$ bond lengths are different $[\mathrm{Hg}-\mathrm{Cl}(1)=2.765(2) \AA, \mathrm{Hg}-\mathrm{Cl}(2)=2.662(2) \AA$ and $\mathrm{Hg}$ $\mathrm{Cl}(3)=2.397(2) \AA$ and $\mathrm{Hg}-\mathrm{Cl}(4)=2.401(2) \AA]$ (Table 3) and are quite comparable with the analogous literature values as shown by scatter plot below in Figure 4. 
Table 3. Bond lengths $[\AA]$ for $p$-phenylenediammonium tetrachloromercurate(II).

\begin{tabular}{cccc}
\hline Atoms 1,2 & $\mathrm{d} \mathrm{1,2[ \AA ]}$ & Atoms 1,2 & $\mathrm{d} \mathrm{1,2[ \AA ]}$ \\
\hline $\mathrm{Hg} 1-\mathrm{Cl} 1$ & $2.765(2)$ & $\mathrm{C} 2-\mathrm{H} 2$ & 0.950 \\
$\mathrm{Hg} 1-\mathrm{Cl} 2$ & $2.662(2)$ & $\mathrm{C} 3-\mathrm{C} 4$ & $1.381(1)$ \\
$\mathrm{Hg} 1-\mathrm{Cl} 3$ & $2.397(2)$ & $\mathrm{C} 4-\mathrm{C} 5$ & $1.379(1)$ \\
$\mathrm{Hg} 1-\mathrm{Cl} 4$ & $2.401(2)$ & $\mathrm{C} 4-\mathrm{N} 2$ & $1.463(1)$ \\
$\mathrm{C} 1-\mathrm{C} 6$ & $1.366(1)$ & $\mathrm{C} 5-\mathrm{C} 6$ & $1.401(1)$ \\
$\mathrm{C} 1-\mathrm{C} 2$ & $1.390(1)$ & $\mathrm{Cl} 4-\mathrm{Cl} 4^{\mathrm{i}}$ & $3.628(3)$ \\
$\mathrm{C} 1-\mathrm{N} 1$ & $1.486(1)$ & $\mathrm{Hg}^{\mathrm{ii}}-\mathrm{Hg}$ & $4.404(1)$ \\
$\mathrm{C} 2-\mathrm{C} 3$ & $1.391(1)$ & $\mathrm{C} 3-\mathrm{H} 3$ & 0.950
\end{tabular}

Symmetry codes: (i) 1-x, $y, 0.5-z$; (ii) $-x,-1-y,-z$; (iii) $-1+x,-1+y, z$.

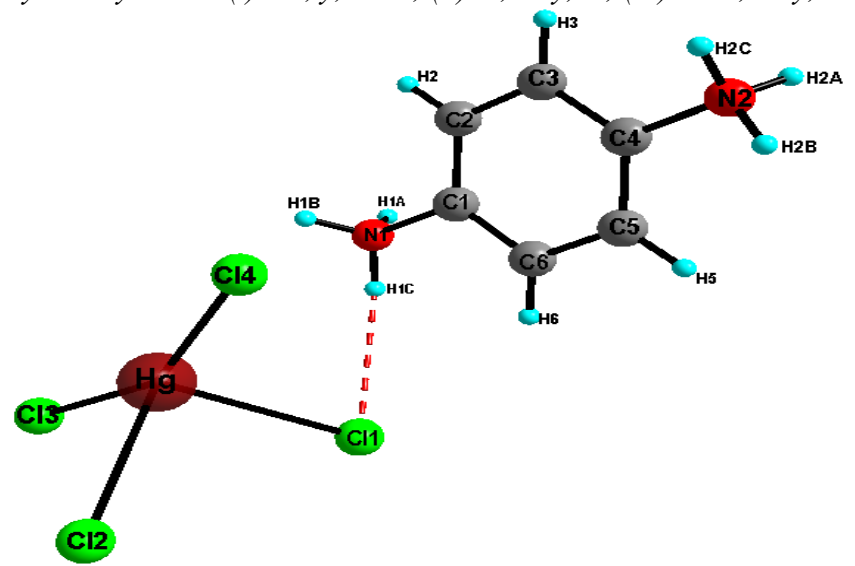

Figure 3. Chemical scheme of $p$-phenylenediammonium tetrachloromercurate(II) showing the atom numbering schemes.

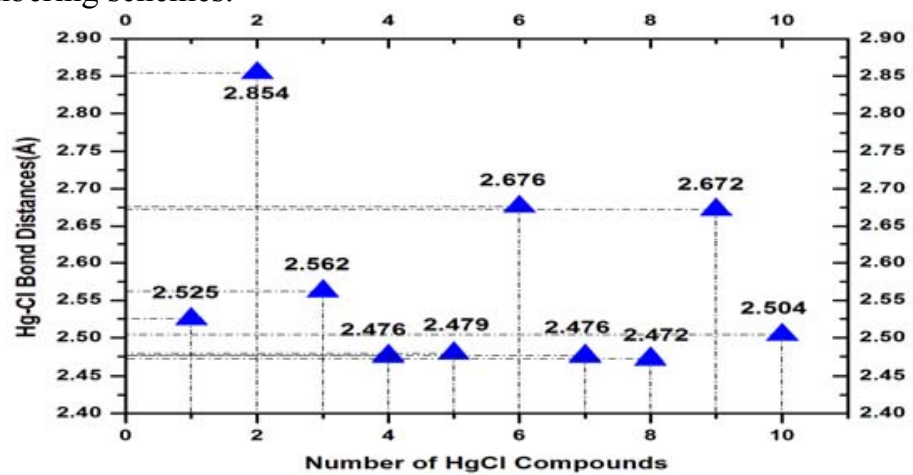

Figure 4. Scatter Plot of $\mathrm{Hg}-\mathrm{Cl}$ bond distances.

The minimum distance between $\mathrm{Hg}-\mathrm{Hg}$ atoms is 4.404(1) $\AA$ which is more than sum of van der Waals radii of $\mathrm{two}^{20} \mathrm{Hg}, 3.50(7) \AA$. Hence, there is no metallophilic $\mathrm{Hg} . . . \mathrm{Hg}$ interaction in this compound as proposed by Das et al., ${ }^{34}$.

One of the main cohesive forces responsible for molecular arrangements of halogen derivatives is the pattern of halogen...halogen intermolecular interactions, and in $p$ phenylenediammonium tetrachloromercurate(II), there is $\mathrm{Cl} 4$...Cl4 halogen interaction with $\mathrm{d}=3.628(3) \AA$. The $\mathrm{Cl}$...Cl4 halogen interaction is weak halogen interaction because sum 
of van der Waals radius of chlorine atom is $3.6 \AA^{35}$. The phenyl ring bond distances and angles are quite comparable with the literature values. The planar ring conformation of phenyl ring has been observed by the skeletal torsion angles having values within $1.15^{\circ}$. The Hydrogen-bonding geometry for $p$-phenylenediammonium tetrachloromercurate(II) has been shown in Table 4 .

Table 4. Hydrogen-bonding geometry for $p$-phenylenediammonium tetrachloromercurate(II)

\begin{tabular}{|c|c|c|c|c|}
\hline D-H...A[ Atoms] & $\mathrm{D}-\mathrm{H}[\AA]$ & $\mathrm{H}-\mathrm{A}[\AA]$ & $\mathrm{D}-\mathrm{A}[\AA]$ & $\mathrm{D}-\mathrm{H} \ldots \mathrm{A}\left[{ }^{0}\right]$ \\
\hline N1-H1A...Cl1 & 0.910 & 2.422 & $3.242(1)$ & 149.90 \\
\hline N1-H1B...Cl2 & 0.910 & 2.178 & $3.072(1)$ & 167.20 \\
\hline $\mathrm{N} 1-\mathrm{H} 1 \mathrm{C} \ldots \mathrm{Cl1}{ }^{\mathrm{i}}$ & 0.910 & 2.526 & $3.386(1)$ & 157.80 \\
\hline $\mathrm{N} 2-\mathrm{H} 2 \mathrm{~A} \ldots \mathrm{Cl} 1^{\mathrm{ii}}$ & 0.910 & 2.642 & $3.376(1)$ & 138.30 \\
\hline $\mathrm{N} 2-\mathrm{H} 2 \mathrm{~A} \ldots \mathrm{Cl} 3^{\mathrm{iii}}$ & 0.910 & 2.642 & $3.272(1)$ & 127.00 \\
\hline $\mathrm{N} 2-\mathrm{H} 2 \mathrm{~B} \ldots \mathrm{Cl} 3^{\mathrm{iv}}$ & 0.910 & 2.404 & $3.314(1)$ & 177.80 \\
\hline $\mathrm{N} 2-\mathrm{H} 2 \mathrm{C} \ldots \mathrm{Cl} 2^{\mathrm{v}}$ & 0.910 & 2.247 & $3.152(1)$ & 173.20 \\
\hline
\end{tabular}

Symmetry points: (i) $-0.5+x,-0.5-y, 0.5+z$ (ii) $-x,-y, 1-z$ (iii) $-0.5+x, 0.5+y, 1+z \quad$ (iv) $-0.5+x,-0.5+y$, $1+z$ (v) $0.5-x, 0.5-y, 1-z$.

There are two linear hydrogen bonds are formed through $\mathrm{H} 2 \mathrm{~B}$ and $\mathrm{H} 2 \mathrm{C}$ with $\mathrm{Cl} 3$ and $\mathrm{Cl} 2$ at symmetry positions $(-0.5+\mathrm{x},-0.5+\mathrm{y}, 1+\mathrm{z})$ and $(0.5-\mathrm{x}, 0.5-\mathrm{y}, 1-\mathrm{z})$, respectively (Table 4$)$. From the inorganic part of hybrid structure, it has been observed that $\mathrm{Cl} 4$ atom is not involved in any hydrogen bonding in contrast to other three chlorine atoms $(\mathrm{Cl} 1, \mathrm{Cl} 2$ and $\mathrm{Cl} 3)$, whereas there is an interesting phenomenon of $\mathrm{Cl} 4 \ldots \mathrm{Cl} 4$ halogen bonding with $\mathrm{Cl}$... Cl [symmetry positions: 1-x, -y, 1-z; x, -y, 0.5+z] distance of 3.628(3) $\AA$ and $\mathrm{Hg}-\mathrm{Cl} \ldots \mathrm{Cl}$ angle of $157.8(9)^{\circ}$.

\section{IR and Raman activity}

The IR, Raman and Hyper-Raman tensors were calculated for the hybrid materials by using crystallographic computing programs ${ }^{36}$ in which selected Wyckoff positions are chosen based on the crystal structure data. The initial Hyper-Raman tensors were calculated by selection rules.

We compute the relative intensities of the hyper-Raman (HR) lines of this as a function of the scattering geometry and from our data we deduce relative values of the HR tensor elements. We interpret the parameters $\partial \chi(2) \mathrm{ij} 1 / \partial u m(\kappa)$ in terms of a nonlinear bondpolarizability model and confirm the dominant role of the such hybrid materials in the nonlinear-optical response. It shows that the hyper-Raman tensors would be useful as a method for studying the band structure in solids through spectroscopic methods ${ }^{37}$.

IR Active Modes: $\left(\Gamma_{\text {acoustic }}=A_{u}+2 B_{u}\right)$

\begin{tabular}{|c|c|c|c|c|}
\hline $\mathrm{WP}$ & $\mathrm{A}_{\mathrm{g}}$ & $\mathrm{A}_{\mathrm{u}}$ & $\mathrm{B}_{\mathrm{g}}$ & $\mathrm{B}_{\mathrm{u}}$ \\
\hline $8 \mathrm{f}$ & $\cdot$ & 3 & $\cdot$ & 3 \\
\hline
\end{tabular}

Raman Active Modes

Hyper-Raman Active Modes
\begin{tabular}{|c|c|c|c|c|}
\hline $\mathrm{WP}$ & $\mathrm{A}_{\mathrm{g}}$ & $\mathrm{A}_{\mathrm{u}}$ & $\mathrm{B}_{\mathrm{g}}$ & $\mathrm{B}_{\mathrm{u}}$ \\
\hline $8 \mathrm{f}$ & $\cdot$ & 3 & $\cdot$ & 3 \\
\hline
\end{tabular}

The polarization selection rule for Raman and Hyper-Raman processes.

Modes activity

This table is a summary of the activity of the different modes of the space group.

\begin{tabular}{|c|c|c|c|c|}
\hline- & $\mathrm{A}_{\mathrm{g}}$ & $\mathrm{A}_{\mathrm{u}}$ & $\mathrm{B}_{\mathrm{g}}$ & $\mathrm{B}_{\mathrm{u}}$ \\
\hline Infrared & $\cdot$ & $\mathrm{x}$ & $\cdot$ & $\mathrm{x}$ \\
\hline Raman & $\mathrm{x}$ & $\cdot$ & $\mathrm{x}$ & $\cdot$ \\
\hline Hyper-Raman & $\cdot$ & $\mathrm{x}$ & $\cdot$ & $\mathrm{x}$ \\
\hline
\end{tabular}

Note: $x=$ represents the modes which can be detected 


\section{Conclusion}

It can be concluded that in $p$-phenylenediammonium tetrachloromercurate(II), the inorganic layers are arranged in zig-zag anti-parallel pattern down b-axis (Figure 5) and are connected to one another through $\mathrm{Cl}$...Cl hydrogen bonded interactions. This phenomenon is quite common in $\mathrm{Hg}$ based hybrid materials as shown in Figure 6 and hence is considered as an important tool stabilizes the crystal structure of desired properties in crystal engineering. Raman spectroscopy is a powerful technique that, in recent years, has been successfully coupled to x-ray crystallography to study the structural parameters in materials. In this paper the complementarily between both techniques is illustrated at structural interpretation with a mechanistic perspective. Such developments have the potential to enhance the relation between crystallographic orientations and Raman tensors which can interpret the combined time-resolved x-ray and Raman crystallographic experiments.

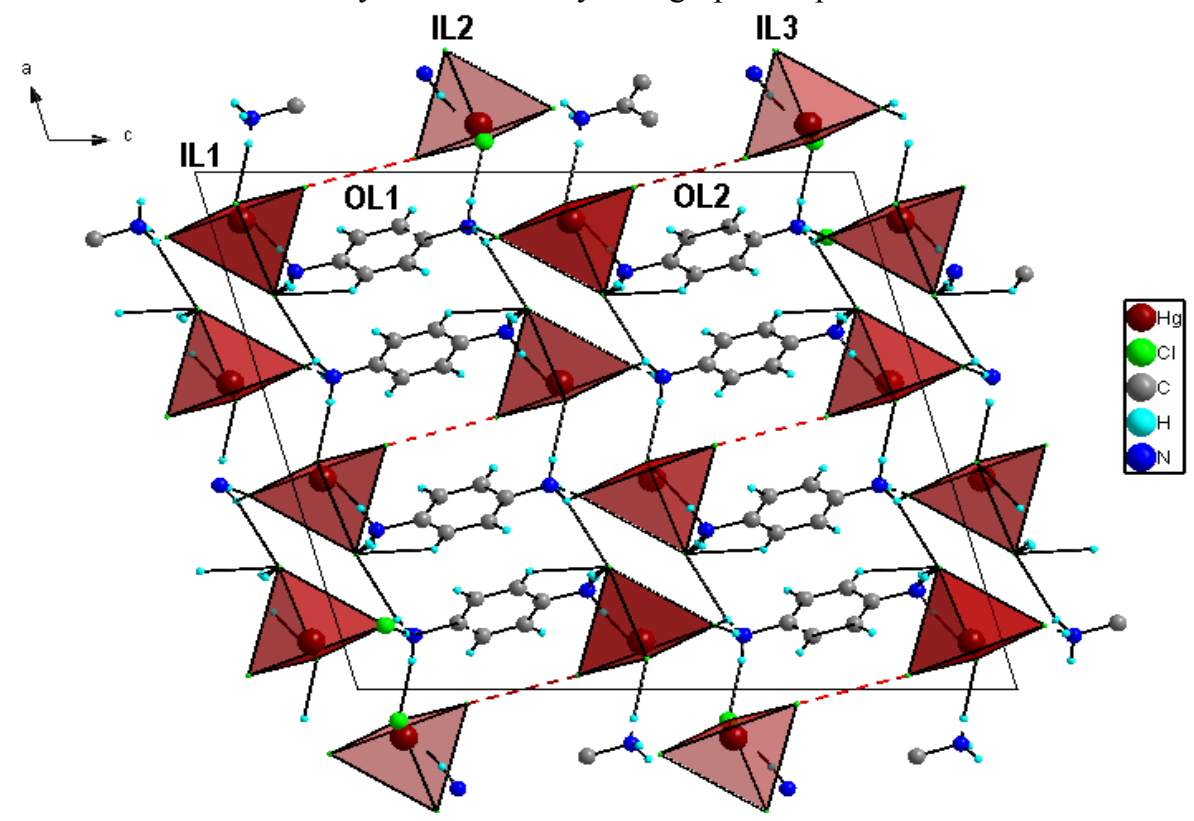

Figure 5. Zig-Zag anti-parallel arrangement of inorganic layers along ac-plane in $p$ Phenylenediammonium tetrachloromercurate(II)

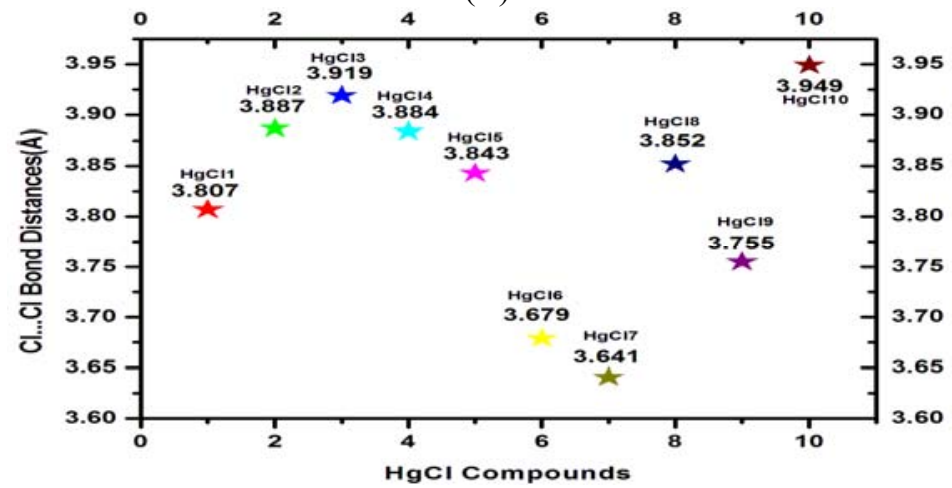

Figure 6. $\mathrm{Cl} \ldots \mathrm{Cl}$ bond distance range in $\mathrm{HgCl}$ derivatives 


\section{Acknowledgment}

The corresponding author Dr. Dinesh Jasrotia and Dr. Sanjay K. Verma are thankful to University Grant Commission, New Delhi (India) for providing financial support under UGC Major Research Project No. 42-777/2013.

\section{References}

1. $\quad$ Mitzi D B, Progress in Inorg Chem., 1999, 48, 1-121.

2. Braga D, Chem Comm., 2003, 2751-2754; DOI:10.1039/B306269B

3. Bourne S A and Mangombo Z, CrystEnggComm., 2004, 6(72), 437-442; DOI:10.1039/b406671e

4. Billing D G and Lemmerer A, CrystEnggComm., 2006, 8, 686-695; DOI:10.1039/B606987H

5. $\quad$ Schmidt G M J, Pure Appl Chem., 1971, 27(4), 647-678;DOI:10.1351/pac197127040647

6. Desiraju G R, Crystal Engineering: The Design of Organic Solids. Elsevier, Amsterdam, 1989.

7. Aakeroy C B and Seddon K R, Chem Soc Rev., 1993, 22, 397-407; DOI:10.1039/CS9932200397

8. Gavezzotti A, J Am Chem Soc., 1991, 113, 4622-4629; DOI:10.1021/ja00012a034

9. Batten S R and Robson R, Angew Chemie., 1998, 110(11), 1558-1595; DOI:10.1002/(SICI)1521-3757(19980605)110:11<1558::AID-ANGE1558>3.0.CO;2-7

10. Batten S R and Robson R, Angew Chem., Int Ed., 1998, 37(11), 1460-1494; DOI:10.1002/(SICI)1521-3773(19980619)37:11<1460::AID-ANIE1460>3.0.CO;2-Z

11. Stang P J, Chem-A Eur J., 1998, 4(1), 19-27; DOI:10.1002/(SICI)15213765(199801)4:1<19::AID-CHEM19>3.0.CO;2-D

12. Blake A J, Champness N R, Hubberstey P, Li W S, Schröder M and Withersby M A, Coord Chem Rev., 1999, 183(1), 117-138; DOI:10.1016/S0010-8545(98)00173-8

13. Moulton B and Zaworotko M J, Chem Rev., 2001, 101(6), 1629-1658; DOI:10.1021/cr9900432

14. Oh M, Carpenter G B and Sweigart D A, Angew Chem., Int Ed., 2003, 42(18), 20262028; DOI:10.1002/anie.200250637

15. Tong M L, Chen X M, Ye B H and Ji L N, Angew Chem., 1999, 111(15), 2376-2379; DOI:10.1002/(SICI)1521-3757(19990802)111:15<2376::AID-ANGE2376>3.0.CO;2-I

16. Tong M L, Chen X M, Ye B H and Ji L N, Angew Chem., Int Ed., 1999, 38(18), 2237-2240;DOI:10.1002/(SICI)1521-3773(19990802)38:15<2237::AID-

ANIE2237>3.0.CO;2-9

17. Che C M, Mao Z, Miskowski V M, Tse M C, Chan C K, Cheung Phillips K K and Leung D L, Angew Chem., 2000, 112(22), 4250-4254; DOI:10.1002/15213757(20001117)112:22<4250::AID-ANGE4250>3.0.CO;2-C

18. Che C M, Mao Z, Miskowski V M, Tse M C, Chan C K, Cheung Phillips K K and Leung D L, Angew Chem., Int Ed., 2000, 39(22), 4084-4088; DOI:10.1002/15213773(20001117)39:22<4084::AID-ANIE4084>3.0.CO;2-N

19. Liu S Q, Kuroda-Sowa T, Konaka H, Suenaga Y, Maekawa M, Mizutani T, Ning G L and Munakata M, Inorg Chem., 2005, 44(4), 1031-1036; DOI:10.1021/ic0400585

20. Pyykko P, Chem Rev., 1997, 97(3), 597-636; DOI:10.1021/cr940396v

21. Jeffrey G A, An Introduction to Hydrogen Bonding. (Oxford:OUP), 1997.

22. Desiraju G R and Steiner T, The Weak Hydrogen Bond in Structural Chemistry and Biology (Oxford:OUP), 1999. 
23. Metrangolo P, Neukirch H, Pilati T and Resnati G, Acc Chem Res., 2005, 38(5), 386395; DOI:10.1021/ar0400995

24. Pedireddi V R, Reddy D S, Goud B S, Craig D C, Rae A D and Desiraju G R, $J$ Chem Soc., Perk Trans., 1994, 2, 2353-2360; DOI:10.1039/P19940002353

25. Bui T T T, Dahaoui S, Lecomte C, Desiraju G R and Espinosa E, Angew Chem., Int Ed., 2009, 48(21), 3838-3841; DOI:10.1002/anie.200805739

26. Brammer L, Espallargas G M and Libri S, CrystEngComm., 2008, 10, 1712-1727; DOI:10.1039/B812927D

27. Dinesh, Redemeyer M, Kumar M and Dalela S, AIP Conf Proc., 2011, 1393(1), $227-$ 228; DOI: $10.1063 / 1.3653692$

28. Kumar M, Dalela S and Dinesh, AIP Conf Proc., 2013, 1536, 771-772; DOI: $10.10634810455 / 1$

29. Dinesh, Kumar M and Dalela S, AIP Conf Proc., 2014, 1591, 1247-1249; DOI: $10.1063 / 1.4872919$

30. Jasrotia D, Rademeyer M, Billing D G and Lemmerer A, Acta Cryst., 2008, E64(12), m1598; DOI:10.1107/S1600536808038415

31. Arend H, Huber W, Mischgofsky F H and Richter-van Leeuwen G K, J Cryst Growth, 1978, 43(2), 213-223; DOI:10.1016/0022-0248(78)90170-7

32. Sheldrick G M, SHELXS97, Program for Crystal Structure Solution. University of G*ottingen, Germany, 1997.

33. Sheldrick G M, SHELXL97, Program for crystal structure refinement. University of G”ottingen, Germany, 1997.

34. Das S, Hung $\mathrm{C} \mathrm{H}$ and Goswami S, Inorg Chem., 2003, 42(25), 8592-8597; DOI:10.1021/ic034948g

35. Bujak M, Dziubek K and Katrusiak A, Acta Cryst., 2007, B63(1), 124-131; DOI:10.1107/S0108768106046684

36. Aroyo M I, Perez-Mato J M, Capillas C, Kroumova E, Ivantchev S, Madariaga G, Kirov $\mathrm{A}$ and Wondratschek $\mathrm{H}, \quad Z$ fur Krist., 2006, 221(1), 15-27; DOI:10.1524/zkri.2006.221.1.15

37. Denisov V M, Mavrin B N and Podovelo V P, Phys Rep., 1987, 151(1), 1-92; DOI:10.1016/0370-1573(87)90053-6 